Buana Sains Vol 19 No 1 : 25 - 36, 2019

\title{
ANALISIS BAURAN PEMASARAN TERHADAP PERILAKU KONSUMEN DAGING SAPI DAN IMPLIKASI STRATEGI PEMASARAN DI HYPERMART KOTA MALANG
}

\author{
Farida Kusuma Astuti, Karunia Setyowati Suroto dan Erik Priyo Santoso
}

Program Studi Peternakan, Fakultas Pertanian, Universitas Tribhuwana Tunggadewi

\begin{abstract}
This research is attempt to bring out marketing mix that dominate the consumer behavior in purchasing beef, to know marketing factors model that recognized by consumer to purchase the beef and to know what marketing strategy implemented by Hypermart MATOS. The research conducted from May to July 2018 involving 100 respondents. A purposive sampling methods was carefully used in determining respondents. Research is conducted by gathering data from primary source that is questionnaire and secondary source directly collected from the firm. Primary data analysis processed in order to highlight factor model that considered by consumer and SWOT analysis to describe company's condition in specifying marketing strategy.

The result shows that marketing mix most considered by consumer to purchase the beef including the product it self, place and promotions influences 26,414 percent, 26,165 percent and 22,778 percent, respectively. Factor model we considered including: factor 1 : competitive price and product it self such variable X5 (flavor), X7 (color), X8 (expiration date), X11 (price changes); factor 2 : the package involving variable X1 (packaging form), X2 (the package easy to open), and X3 (packaging materials); factor 3 : display product on show case as variable X4 (product display). Each factor model has their impacts 33,474 percent, 14,948 percent and 11,413 percent, respectively. Marketing strategy growth and build consists of market penetration by selling product in lower price to market segment which is sensitive to price, product development (diversification) referred to product factor model and price comparison, packaging and displays by giving recipes information from each type of beef and market development in order to fit demography condition and beef consumer characteristics in Malang.

Keywords: Beef; consument behaviour; hypermart; marketing mix; purchasing.

\section{Pendahuluan}

Daging sapi merupakan bahan pangan yang sudah menjadi kebutuhan pokok sehari-hari bagi masyarakat saat ini, terutama masyarakat yang tinggal dan menetap di kota besar. Daging sapi merupakan salah satu bahan pangan yang hampir sempurna, karena mengandung gizi yang lengkap. Daging sapi mengandung sumber protein bermutu

tinggi (asam-asam amino esensial), lemak, vitamin B komplek, mineral khusunya zat besi dan air yang diperlukan untuk pertumbuhan dan perkembangan tubuh.

Daging sapi yang dikemas dalam berbagai macam jenis potongan, didistribusikan kepada konsumen melalui berbagai macam saluran distribusi, salah satunya pasar modern Hypermart Malang Town Square (MATOS) yang berdiri di Kota Malang. Masa yang akan datang
\end{abstract}


F. K. Astuti, K.S. Suroto dan E. P. Santoso/ Buana Sains Vol 19 No 1 : 25-36

usaha eceran di indonesia, khususnya toko eceran modern berbentuk swalayan akan mengalami pertumbuhan yang cukup baik. Disebabkan oleh sikap konsumen yang selalu ingin mendapatkan sesuatu yang lebih baik dengan pengorbanan yang relatif lebih kecil (pay less, accept more, get more), serta ditunjang oleh peningkatan jumlah keluarga yang memiliki penghasilan ganda (double income family), perubahan gaya hidup konsumen akibat keinginan untuk mengikuti gengsi, pemekaran wilayah perkotaan, perpindahan penduduk dan kemajuan teknologi komunikasi.

Semakin meningkatnya penjualan daging sapi secara pasar modern maupun tradisional mengakibatkan adanya persaingan yang ketat untuk memperoleh pangsa pasar penjualan. Strategi pemasaran yang tepat sangat diperlukan untuk meningkatkan pangsa pasar dan volume penjualan. Perusahaan dalam mencapai tujuan untuk memenuhi kebutuhan konsumen, diperlukan adanya analisis perilaku konsumen sebagai salah satu strategi pemasaran. Mempelajari dan menganalisa perilaku konsumen dalam keputusan pembelian adalah hal yang penting, sebab dengan pengetahuan dasar yang baik mengetahui perilaku konsumen akan dapat memberi masukan yang berarti bagi perencanaan strategi pemasaran. Sebagai seorang pemasar harus melaksanakan kegiatan pemasaran yang sesuai dengan keinginan dan kebutuhan konsumen.

Proses pengambilan keputusan untuk membeli suatu produk berupa daging sapi, konsumen akan dipengaruhi oleh beberapa faktor bauran pemasaran (marketing mix) yang terdiri dari produk, harga, promosi, dan tempat. Tidak seluruh variabel bauran pemasaran yang ditampilkan oleh perusahaan akan dipertimbangkan oleh konsumen dalam memutuskan untuk membeli suatu produk. Perusahaan Hypermart MATOS harus mengetahui variabel bauran pemasaran yang menjadi pertimbangan konsumen dan variabel bauran pemasaran apa yang paling dominan mempengaruhi keputusan pembelian daging sapi.

\section{Metode Penelitian}

Penelitian perilaku konsumen daging sapi dan implikasinya pada strategi pemasaran ini mengambil lokasi di Hypermart MATOS. Responden penelitian adalah konsumen daging sapi yang membeli langsung di Hypermart MATOS. Untuk menentukan jumlah besarnya sampel dari suatu populasi, Roscoe (1975) dalam sekaran (2006) berpendapat bahwa dalam penelitian mulivariat, ukuran sampel sebaiknya 4 atau 5 kalinya dari jumlah variable penelitian. Sehingga dapat ditentukan jumlah responden yang diambil sebanyak 84 orang konsumen atau responden.

Pengambilan sampel dilakukan secara purposive sampling yaitu pengambilan sampel berdasarkan pada konsumen yang membeli daging sapi di Hypermart MATOS pada saat itu, dengan pertimbangan untuk memperoleh gambaran yang menyeluruh tentang konsumen. Sampel diambil dengan memperhatikan pengaruh waktu terhadap perilaku pembelian konsumen yaitu awal bulan, tengah bulan dan akhir bulan, akhir pekan (Sabtu-Minggu) dan hari kerja (Senin-Jum'at); jam kantor $(08.00$ - 12.00 dan $14.00-17.00)$ dan jam istirahat $(12.00-14.00$ dan 17.00 21.00).

\section{Metode Pengumpulan Data}

Pengumpulan data merupakan teknik dalam menggali data dilapangan. Data yang digunakan dalam penelitian ini diperoleh dari dua sumber, yaitu: 


\section{Data primer}

Data primer diperoleh langsung dari pihak pertama (responden), yaitu diperoleh melalui wawancara langsung dengan responden yang terpilih dengan menggunakan daftar pertanyaan yang telah disiapkan (kuesioner). Data primer ini merupakan data pokok dalam analisis serta data mengenai karakteristik demografi responden dalam membeli daging sapidi Hypermart MATOS dan faktor-faktor yang mempengaruhi.

2. Data Skunder

Data skunder digunakan untuk mendukung data primer yang tidak diusahakan sendiri pengumpulannya oleh peneliti, tetapi sudah bentuk jadi dan sudah diolah. Data skunder diperoleh dari dokumen yang dimiliki Hypermart MATOS untuk mengetahui keadaan umum lokasi penelitian, media cetak dan elektronik, serta jurnal dan penelitian ilmiah yang sejenis sebagai referensi.

\section{Instrumen Pengumpulan Data}

Instrumen untuk pengumpulan data dalam penelitian ini adalah angket atau kuisioner yang disusun berdasarkan kisi-kisi teoritis dalam bentuk skala likert. Berdasarkan format yang disusun oleh Rensis Likert, yang dikutip oleh Parasurahman (1991), skala likert terdiri dari seperangkat pertanyaan-pertanyaan memiliki lima poin skala setuju-tidak setuju. Jumlah pertanyaan-pertanyaan yang dibuat dalam skala bervariasi, tergantung pada berapa banyak karakteristik dari obyek yang relevan dengan penelitian. Kuisioner yang disusun mengikuti skala likert penentuanskornya sebagai berikut:

1. Sangat mempertimbangkan : skor 5

2. Mempertimbangkan : skor 4

3. Cukup mempertimbangkan : skor 3

4. Kurang mempertimbangkan: skor 2

5. Tidak mempertimbangakan : skor 1

\section{Identifikasi Variabel}

Sesuai dengan variabel perumusan masalah, tujuan penelitian, tinjauan pustaka maka ditentukan variabel-variabel penelitian sebagai berikut:

1. Variabel-variabel yang terkait dengan produk

$$
\begin{aligned}
& \mathrm{x}_{1}: \text { bentuk kemasan } \\
& \mathrm{x}_{2}: \text { kepraktisan membuka kemasan } \\
& \mathrm{x}_{3}: \text { bahan kemasan } \\
& \mathrm{x}_{4}: \text { display produk } \\
& \mathrm{x}_{5}: \text { aroma } \\
& \mathrm{x}_{6}: \text { bentuk potongan } \\
& \mathrm{x}_{7}: \text { warna } \\
& \mathrm{x}_{8}: \text { label kadaluarsa } \\
& \mathrm{x}_{9}: \text { label netto } \\
& \mathrm{x}_{10}: \text { variasi/jenis potongan }
\end{aligned}
$$

2. Variabel-variabel yang terkait dengan harga

$\mathrm{x}_{11}$ : perbandingan harga daging sapi dengan tempat lain

$\mathrm{x}_{12}$ : persepsi harga

$\mathrm{x}_{13}$ : perubahan harga

3. Variabel-variabel yang terkait dengan promosi

$\mathrm{x}_{14}$ : frekuensi mendapatkan iklan

$\mathrm{x}_{15}$ : daya tarik iklan

$\mathrm{x}_{16}$ : fasilitas MCC

4. Varibel-variabel yang terkait dengan tempat

$\mathrm{x}_{17}$ : kenyamanan tempat

$\mathrm{x}_{18}$ : keramahan penjual

$\mathrm{x}_{19}$ : jarak lokasi

$\mathrm{x}_{20} \quad$ :setelah berkunjung

keHypermart

$\mathrm{x}_{21}$ : panjang antrean di kassa

\section{Metode Analisa Data}

Data dianalisis secara deskriptif kuantitatif dan kualitatif. Deskriptif kuantitatif yaitu dengan menggunakan uji analisis validitas, analisis reliabelitas dan teknik analisis faktor. Sedangkan deskriptif kualitatif digunakan untuk merumuskan strategi pemasaran 
F. K. Astuti, K.S. Suroto dan E. P. Santoso/ Buana Sains Vol 19 No 1 : 25-36

Hypermart Malang Town Square dengan menggunakan analisis Strengths, Weaknesses, Opportunities, Threats (SWOT).

\section{Analisis SWOT}

Deskriptif kualitatif adalah untuk mengetahui rumusan strategi pemasaran dengan SWOT analisis. Analisis ini digunakan untuk melihat kekuatan dan kelemahan di lingkungan internal serta melihat peluang dan ancaman dari lingkungan eksternal perusahaan.

Dengan dasar informasi yang dikumpulkan tersebut, maka akan dapat disusun perencanaan bisnis yang sesuai dengan formulasi bisnis yang telah ditentukan seperti misi, tujuan, strategi dan kebijakan atau keputusan. Analisis SWOT digunakan untuk mengatasi kelemahan, memperkecil ancaman dan meningkatkan kekuatan dalam upaya meraih dan mendapatkan kesempatan atau peluang sebesar mungkin.

Selanjutnya secara teoristis untuk melihat posisi suatu lembaga atau peusahaan maka dapat dilakukan dengan mengamati diagram analisis SWOT yang berbentuk empat kuadran sebagai berikut:

Kuadran 1: Ini merupakan situasi yang sangat menguntungkan, karena perusahaan mempunyai peluang dan kekuatan sehingga dapat memanfaatkan peluang yang ada. Strategi yang harus diterapkan dalam kondisi ini adalah mendukung kebijakan pertumbuhan yang agresif.

Kuadran 2: Perusahaan menghadapi berbagai ancaman tapi masih memilki kekuatan dari segi internal. Strategi yang harus diterapkan adalah menggunakan

$$
\begin{array}{lr}
\text { kekuatan } & \text { untuk } \\
\text { memanfaatkan peluang } & \text { jangka panjang dengan } \\
\text { jangategi diversifikasi. }
\end{array}
$$

Kuadran 3: Perusahaan menghadapi peluang pasar yang sangat besar, tetapi dilain pihak ia mengahadapi kendala atau kelemahan internal. Fokus strategi perusahaan ini adalah meminimalkan masalah-masalah internal perusahaan sehingga dapat merebut peluang pasar yang lebih baik.

Kuadran 4: Ini merupakan situasi yang sangat tidak menguntungkan, dimana perusahaan mengahadapi berbagai ancaman dan kelemahan internal

\section{Hasil dan Pembahasan}

\section{Bauran Pemasaran Daging Sapi di Hypermart Malang Town Square}

Berikut ini adalah bauran pemasaran daging sapi di Hypermart MATOS yang terdiri dari bauran produk, promosi, harga dan tempat.

\section{Faktor Bauran Produk}

Alat bauran pemasaran paling mendasar adalah produk. Ritel harus memperhatikan elemen produk, yakni keluasan dan kedalaman serta keragaman produk, semakin lengkap semakin baik. Salah satu atribut yang penting adalah kualitas dari sebuah produk itu sendiri, karena hanya produk yang berkualitas baik yang dapat bersaing dalam dunia usaha. Daging sapi adalah produk yang mudah terkontaminasi dengan mikroba pembusuk, sehingga proses perlakuan harus tetap terjaga.

Dalam usahanya memperoleh produk daging sapi yang berkualitas, perusahaan Hypermart MATOS melakukan pengawasan yang ketat dalam proses produksi dan hasil produksi. Pengawasan dilakukan mulai dari pengadaan, 
penyimpanan, penanganan dan pemasaran. Hal ini dilakukan agar hasil produksi yang diperoleh dapat optimal baik kuantitas maupun kualitasnya. Pemeriksaan secara kualitas terdiri dari keempukan atau kelunakan, kandungan lemak atau marbling, warna, rasa, aroma, dan kelembaban. Menurut Anonymous (2004), kualitas daging dipengaruhi oleh beberapa faktor, baik pada waktu hewan masih hidup maupun setelah dipotong. Pada waktu hewan hidup, faktor penentu kualitas daging pada saat cara pemeliharaan, meliputi pemberian pakan, tata laksana pemeliharaan, dan perawatan kesehatan. Kualitas daging juga dipengaruhi oleh pendarahan pada waktu hewan dipotong dan kontaminasi sesudah hewan dipotong. Karakteristik dan ciri-ciri setiap mutu daging sapi di Hypermart MATOS dapat dilihat pada Tabel 1.

Kriteria daging yang layak dan tidak layak dikonsumsi menurut SOP (Standart Operating Procedure) Hypermart MATOS meliputi, kualitas daging yang baik kriteria yang dapat dipakai sebagai pedoman untuk menentukan kualitas daging yang layak konsumsi adalah sebagai berikut :

a. Keempukan atau kelunakan

Keempukan daging ditentukan oleh kandungan jaringan ikat. Semakin tua usia hewan, susunan jaringan ikat semakin banyak, sehingga daging yang dihasilkan semakin liat. Jika ditekan dengan jari, daging yang sehat akan memiliki konsistensi kenyal (padat).

b. Kandungan lemak

Kandungan lemak atau marbling adalah lemak yang terdapat diantara otot (intramuscular). Lemak berfungsi sebagai pembungkus otot dan mempertahankan keutuhan daging pada waktu dipanaskan. Marbling berpengaruh terhadap cita rasa daging.

c. Warna

Warna daging bervariasi, tergantung dari jenis secara genetik dan usia. Misalnya daging sapi potong lebih gelap daripada daging sapi perah. Daging sapi muda lebih pucat daripada daging sapi dewasa.

d. Rasa dan Aroma

Cita rasa dan aroma dipengaruhi oleh jenis pakan, daging yang berkualitas baik mempunyai rasa yang relatif gurih dan aroma yang sedap.

e. Kelembaban

Secara normal daging mempunyai permukaan yang relatif kering sehingga dapat menahan pertumbuhan mikroorganisme dari luar. Dengan demikian mempengaruhi daya simpan daging tersebut.

Tabel 1. Ciri -Ciri dan Mutu Daging Sapi.

\begin{tabular}{llll}
\hline Karakteristik & Ciri-ciri & & \\
& Mutu I & Mutu II & Mutu III \\
\hline Warna & Merah khas & Merah khas & Merah khas \\
& Daging segar & Daging segar & Daging segar \\
Penampakan & Kering & Lembab & Basah \\
Kekenyalan & Kenyal & Kurang kenyal & Lembek \\
\hline
\end{tabular}

Sumber: Data sekunder Hypermart MATOS.

Daging yang tidak baik daging yang tidak aman dapat membahayakan kesehatan konsumen. Beberapa kriteria daging yang tidak baik adalah sebagai berikut: 
F. K. Astuti, K.S. Suroto dan E. P. Santoso/ Buana Sains Vol 19 No 1 : 25-36

a. Bau dan rasa tidak normal

Bau yang tidak normal biasanya akan segera tercium sesudah hewan dipotong. Hal tersebut dapat disebabkan oleh adanya kelainan-kelaianan sebagai berikut: 1 . Hewan yang sakit, terutama yang menderita radang yang bersifat akut pada organ dalam, akan menghasilkan daging yang berbau seperti mentega tengik. 2. Hewan dalam pengobatan, hewan dalam masa pengobatan terutama dengan pemberian antibiotika akan menghasilkan daging yang berbau obat-obatan.

b. Warna daging tidak normal

Warna daging yang tidak normal tidak selalu membahayakan kesehatan konsumen, namun akan mengurangi selera konsumen.

c. Konsistensi tidak normal

Daging yang tidak sehat mempunyai kekenyalan rendah (jika ditekan dengan jari akan terasa lunak), apalagi diikuti dengan perubahan warna yang tidak normal, maka daging tersebut tidak layak dikonsumsi

d. Daging busuk

Daging sapi yang diperoleh dari supplier dijual oleh Hypermart MATOS sesuai dengan bentuk dan jenis potongan daging sapi. Daging sapi berasal dari perusahaan Q beef Jakarta, perusahaan Fedoratama Surabaya, dan Sukanda Jaya Surabaya. Masing - masing perusahaan bergerak pada bidang distribusi dan pemotongan hewan. Daging sapi berasal dari dalam negeri, Australia dan New Zealand. Pada daging sapi yang berasal dari dalam negeri terdiri dari bangsa sapi ongole, brahman, hasil persilangan sapi simmental dan limousin. Pada daging sapi impor bangsa sapi berasal dari breed murni simmental dan limousin. Proses produksi dari setiap daging sapi terdiri dari 4 tahap yaitu: proses pengadaan, penyimpanan, penanganan dan pemasaran.

\section{Faktor Bauran Harga}

Harga merupakan satu-satunya unsur bauran pemasaran yang memberikan pemasukan atau pendapatan bagi perusahaan, bahkan pada segmen tertentu harga merupakan faktor penentu keputusan pembelian. Bauran pemasaran harga bersifat fleksibel, artinya dapat diubah dengan cepat. Perusahaan Hypermart MATOS menetapkan harga dengan kualitas daging tetap terjaga sesuai dengan harga jual daging sapi.

Proses penetapan harga beli dan harga jual dilakukan oleh MD Buyer pusat, dengan memperhatikan konsistensi, pandangan jangka panjang, tingkat harga dan laba maksimum. Metode penetapan harga dengan menggunakan Mark Up, yaitu strategi harga yang dilaksanakan oleh perusahaan dengan membuat harga jual untuk satu unit dari biaya produksi satu unit produk, ditambah suatu jumlah tertentu untuk menutup laba yang diinginkan

\section{Faktor Bauran Promosi}

Promosi adalah bentuk persuasi langsung melalui penggunaan berbagai intensif yang dapat diatur untuk merangsang pembelian produk dengan segera dan meningkatkan jumlah barang yang dibeli pelanggan. Tujuan dari promosi penjualan agar dapat menarik pelanggan baru, meningkatkan pembelian tanpa rencana sebelumnya, dan menyerang aktivitas promosi pesaing. Pelaksanaan promosi penjualan yang dilakukan oleh Hypermart Malang Town Square menggunakan tiga alat promosi penjualan yaitu :

a. Promosi Konsumen.

Alat promosi penjualan yang digunakan adalah pajangan dan hadiah.

b. Promosi Perdagangan.

Alat promosi penjualan yang digunakan adalah melalui potongan 
harga. Tujuan alat ini adalah untuk mendorong konsumen untuk membeli produk secara lebih cepat dan atau banyak mengingat insentif promosi penjualan bersifat sementara.

c. Promosi Bisnis atau Wiraniaga.

Alat promosi yang digunakan adalah pameran dagang.

Elemen promosi berkaitan dengan periklanan, publisitas dan hubungan masyarakat. Ritel dengan format toko (store retailer), lebih mengoptimalkan penggunaan katalog maupun direct mail untuk promosi atau berinteraksi dengan konsumen. Hypermart MATOS dalam melakukan promosi terhadap produk lebih mengoptimalkan katalog yang berisi promo produk, memasang iklan di media lokal atau membagikan band out flyers untuk promosi pada event spesial seperti tahun baru, Hari Raya Idul Fitri, dll.

Pelaksanaan periklanan yang dilakukan oleh Hypermart MATOS menggambarkan bahwa iklan yang digunakan merupakan media iklan lini atas (above the line media) dan media iklan lini bawah (below the line media). Hal tersebut sesuai dengan pendapat Kasali (1992), berdasarkan media iklan yang digunakan yang merupakan media lini atas adalah POP (Purchase of Product) berukuran A7, A3, dan A2, wobler, audio promo Hypermart Malang, Audio building Matos, TV lokal, Giant Barner, spanduk, Hanging Mobile dan surat kabar. Sedangkan yang merupakan media lini bawah adalah katalog, poster, dan leaflet. Pada departemen Meat and Fish dalam menjual daging, periklanan dilakukan dengan media POP (Purchase of Product) berukuran A7, A3, dan A2, wobler, audio promo Hypermart Malang, Audio building Matos, surat kabar, katalog, poster, dan leaflet.

\section{Faktor Bauran Tempat}

Lokasi adalah faktor utama dalam pemilihan toko untuk konsumen. Ini juga keunggulan bersaing yang tidak dengan mudah ditiru. Hypermart selalu menentukan lokasi di daerah strategis. Selain itu, lokasi di daerah strategis memudahkan dalam memperkirakan pengiriman, yang nantinya barang-barang dipastikan segar dan baik. Pemilihan lokasi yang tepat mempunyai keuntungan yaitu merupakan komitmen sumber daya jangka panjang yang dapat mengurangi fleksibilitas masa depan ritel itu sendiri.

Hypermart MATOS berada pada tempat yang strategis di tengah pusat keramaian dan perumahan penduduk. Lokasi di pilih mempertimbangkan kedekatan dengan konsumen, kemudahan jangkauan, jarak dengan pemasok yang mempengaruhi kontinuitas pengiriman barang jualan, fasilitas tempat, ATM, dan lahan parkir. Letak Departemen Meat and Fish berada di area yang paling belakang menjadi satu jenis produk fresh food dalam keadaan dan kondisi yang aman dan bersih.

\section{Pengaruh Faktor Bauran Pemasaran (Marketing Mix)}

Bauran pemasaran terdiri dari produk, harga, promosi dan tempat (saluran pemasaran) dari keempat bauran tersebut memiliki pengaruh yang hampir sama terhadap keputusan konsumen membeli produk daging sapi di Hypermart MATOS. Persentase pengaruh masing-masing faktor bauran pemasaran dapat dilihat pada tabel 2 berikut: 
F. K. Astuti, K.S. Suroto dan E. P. Santoso/ Buana Sains Vol 19 No $1: 25-36$

Tabel 2. Pengaruh masing-masing faktor bauran pemasaran terhadap perilaku konsumen daging sapi dan implikasi strategi pemasaran di hypermart kota malang

\begin{tabular}{lll}
\hline Faktor Marketing Mix & Nilai Rata-rata & Persentase (\%) \\
\hline Produk & 3,653 & 26,414 \\
Harga & 3,407 & 24,643 \\
Promosi & 3,150 & 22,777 \\
Tempat & 3,620 & 26,175 \\
Jumlah & 13,832 & 100 \\
\hline
\end{tabular}

Sumber : Data Primer (Diolah), 2008

Dari tabel 2 menunjukkan bahwa pengaruh paling dominan terhadap pengambilan keputusan konsumen dalam membeli daging sapi di Hypermart MATOS adalah bauran produk sebesar 26,414 persen yang mempengaruhi pembelian daging sapi. Bauran produk daging sapi menjadi prioritas utama karena mengingat keadaan daging sapi yang mudah rusak akibat kontaminasi mikroba dan waktu penanganan, sehingga konsumen harus menyeleksi daging sapi sebelum memutuskan untuk membeli.

Pertimbangan yang kedua dalam membeli daging sapi di Hypermart adalah bauran pemasaran tempat sebesar 26,165 persen yang mempengaruhi pembelian daging sapi. Lokasi dan model interior adalah faktor utama dalam pemilihan toko yang menjadi keunggulan para konsumen dalam berbelanja. Belanja secara mudah dan praktis menjadi kebutuhan konsumen saat ini. Selain untuk memenuhi kebutuhan rumah tangga, ritel sebagai sarana berlibur di akhir pekan. Sehingga penataan tempat dan ruang belanja harus ditentukan sesuai dengan kebutuhan konsumen saat ini.

Bauran harga memiliki persentase ketiga sebelum bauran tempat sebesar 24,643 persen yang mempengaruhi konsumen dalam membeli daging sapi. Persaingan antar perusahaan ritel di Malang sangat ketat, sehingga konsumen memiliki nilai daya tawar tinggi dalam membeli daging sapi terhadap harga yang ditetapkan. Pertimbangan terakhir dalam pengambilan keputusan membeli daging sapi adalah bauran promosi sebesar 22,778 persen yang mempangaruhi konsumen dalam membeli daging sapi.

\section{Uji Instrumen Penelitian}

\section{Uji Validitas}

Sebelum dilakukan faktoring perlu dilakukan pengujian atas validitas dan reliabilitas dari instrumen penelitian. Dalam Arikunto (2002) validitas adalah suatu ukuran yang menunjukkan tingkattingkat kevalidan atau kesahihan suatu instrumen. Validitas menunjukkan sejauh mana alat pengukur dapat mengukur apa yang ingin diukur atau dengan kata lain, instrumen tersebut dapat mengukur sesuai dengan apa yang diharapkan oleh peneliti. Suatu instrumen dapat dikatakan memiliki validitas yang tinggi apabila instrumen tersebut dapat menjalankan fungsi ukurnya atau memberikan hasil ukur yang tepat dan akurat.

Valid tidaknya suatu item instrumen dapat diketahui dengan membandingkan indeks korelasi Product Moment Pearson dengan level signifikansi 5\%. Apabila probabilitas hasil korelasi lebih kecil dari 0,05 (5\%), maka instrumen dinyatakan valid dan apabila probabilitas hasil korelasi lebih besar dari $0,05(5 \%)$, maka instrumen dinyatakan tidak valid. Dan juga jika nilai korelasinya (r) lebih besar dari 0,3 maka hasil penelitian dapat dikatakan valid, (Masrun dalam Sugiyono, 2005). 
Tabel 3. Hasil uji reliabilitas instrumen terhadap perilaku konsumen daging sapi dan implikasi strategi pemasaran di hypermart kota malang

\begin{tabular}{|c|c|c|c|c|}
\hline Marketing Mix & $\begin{array}{l}\text { Koefisien } \\
\text { Cronbach }\end{array}$ & Alpha & $\begin{array}{l}\text { Tingkat } \\
\text { Hubungan }\end{array}$ & Keterangan \\
\hline Produk & 0,756 & & Kuat & Reliabel \\
\hline Harga & 0,738 & & Kuat & Reliabel \\
\hline Promosi & 0,766 & & Kuat & Reliabel \\
\hline Tempat & 0,681 & & Kuat & Reliabel \\
\hline
\end{tabular}

Sumber : Data primer diolah, 2008.

Dari Tabel 3 diketahui bahwa variabel marketing mix atau bauran pemasaran yang terdiri produk, harga, promosi dan tempat mempunyai koefisien Alpha Cronbach lebih dari 0,60. Jadi dapat disimpulkan instrumen dalam penelitian ini dinyatakan reliabel.

\section{Uji Validitas dan Realibilitas Model} Faktor

Validitas faktor dapat ditafsirkan berdasarkan koefisien gamma (faktor loading). Suatu faktor dikatakan valid jika memiliki faktor loading $>0,6$. Hasil rotasi faktor pada lampiran 26 memberikan informasi mengenai validitas tiga faktor yang terbentuk. Faktor tersebut dinyatakan valid karena seluruh variabel yang mendukung faktorfaktor memiliki faktor loading $>0,6$. Validitas sebuah faktor menjelaskan bahwa sekelompok variabel yang mendukung sebuah faktor tersebut adalah koheren, artinya dari satu konsep yang sama.

Kelompok variabel yang mewakili sebuah faktor perlu diuji tingkat reliabilitas yang dicapai. Penghitungan reliabilitas faktor dapat dilihat pada lampiran 26 sesuai dengan rumus yang dikemukakan oleh Kim dan Mueller (1995).

Dari hasil uji reliabilitas model faktor dapat disimpulkan bahwa 3 model faktor adalah reliabel karena memiliki nilai koefisien reabilitas lebih dari 0,6. Artinya faktor dapat diandalkan atau dapat memberikan hasil model faktor yang tidak berbeda bila dilakukan pengukuran kembali terhadap subyek yang sama.

\subsection{Interprestasi Faktor}

Interprestasi hasil faktor mengacu pada hasil analisis matrik komponen rotasi setelah reduksi pada lampiran 23. Pada lampiran tersebut nampak bahwa 9 variabel yang ada tersebar pada tiga faktor dengan total varian (commulative persentage) sebesar 59,844 persen dan dengan kisaran faktor loading antara 0,630 hingga 0,875.

\subsubsection{Faktor 1 (Produk dan harga)}

Model faktor 1 yang paling dipertimbangkan konsumen dalam membeli daging sapi terdiri dari variabel X5 (aroma), X7 (warna), X8 (label kadaluarsa), $\mathrm{X}_{11}$ (perbandingan harga) dengan faktor loading masing-masing sebesar 0,672, 0,783, 0,635 dan 0,703. Faktor ini memiliki eigen value tertinggi sebesar 3,013 dan mampu menjelaskan keragaman (varian) variabel-variabel sebesar 33,472 persen.

Model faktor 1 berasal dai konsep bauran produk dan harga, sehingga berdasarkan konsep tersebut faktor 1 disebut faktor produk dan harga. Daging sapi mudah rusak dan tidak tahan lama sehingga konsumen mempertimbangkan aroma, warna, label kadaluarsa dan perbandingan harga daging sapi.

Konsumen dalam membeli daging mempertimbangkan harga dari 
F. K. Astuti, K.S. Suroto dan E. P. Santoso/ Buana Sains Vol 19 No 1 : 25-36

pesaingnya. Sehingga harga yang ditetapkan harus tepat dalam menentukan jumlah harga jual yang ditawarkan kepada konsumen dengan tingkat harga yang bersaing. Harga daging yang mengalami diskon pada waktu week end akan merangsang konsumen untuk memasuki toko untuk membeli produk lainnya. Konsumen akan semakin pandai dalam menentukan harga beli daging sapi mengingat tingginya persaingan bisnis retail yang ada di Malang.

\subsubsection{Faktor 2 (Kemasan Produk)}

Faktor 2 yang dipertimbangkan konsumen dalam membeli daging sapi terdiri dari variabel X1 (bentuk kemasan), $\mathrm{X} 2$ (kepraktisan membuka kemasan) dan $\mathrm{X}_{3}$ (bahan kemasan) dengan faktor loading brturut-turut sebesar 0,827, 0,769, 0,630. Faktor 2 berasal dari variabel konsep bauran kemasan, sehingga disebut sebagai faktor kemasan, dengan eigen value sebesar 1,346 dengan persentase sebesar 14,958 persen yang artinya faktor kemasan dapat memberikan sumbangan sebesar 14,958 persen dalam membeli daging sapi di Hypermart MATOS.

Kemasan (packaging) menjadi wadah yang sangat penting untuk membungkus produk daging sapi agar awet dan tahan lama yang sesuai dengan terget penjualan yang diinginkan. Kemasan yang membungkus daging sapi harus mengutamakan material dan rancangan yang dapat melindungi kerusakan dan dapat memikat konsumen untuk membeli. Kemasan yang digunakan oleh Hypermart MATOS menggunakan bahan stryofoam dan plastik. Kemasan yang didesain dengan menarik mampu menjadi nilai promosi untuk menciptakan nilai tersendiri bagi konsumen. Hasil dari analisis faktor, faktor 2 menunjukkan bahwa konsumen sangat memperhatikan bentuk kemasan, kepraktisan membuka kemasan dan bahan kemasan.

\subsubsection{Faktor 3 (display produk)}

Faktor 3 yang dipertimbangkan konsumen terhadap keputusan pembelian daging sapi adalah variabel $\mathrm{X}_{4}$ (display produk), dengan faktor loading sebesar 0,875 . Variabel faktor 3 berasal dari konsep atribut kemasan produk. Faktor tiga memiliki eigen value sebesar 1,027 dengan angka persentase yang mempengaruhi faktor 3 sebesar 11,413 persen. Display yang rapi dan menarik pada showcase sangat mempengaruhi pembelian daging sapi di Hypermart MATOS, sehingga konsumen akan merasa nyaman dalam berbelanja.

\section{Kesimpulan}

1. Bauran pemasaran yang paling dominan dipertimbangkan konsumen adalah produk dengan persentase $(26,41$ $\%)$, tempat $(26,16 \%)$, harga $(24,64 \%)$, dan promosi $(22,77 \%)$ yang mempengaruhi konsumen dalam pembelian daging sapi di Hypermart MATOS.

2) Model faktor yang dipertimbangkan konsumen adalah produk dan harga yang terdiri dari variabel $\mathrm{X}_{5}$ (aroma), $\mathrm{X}_{7}$ (warna), $\mathrm{X}_{8}$ (label kadaluarsa), $\mathrm{X}_{13}$ (perbandingan harga) dengan persentase $(33,472 \%)$, kemasan yang terdiri dari $\mathrm{X}_{1}$ (bentuk kemasan), $\mathrm{X}_{2}$ (kepraktisan membuka kemasan), $\mathrm{X}_{3}$ (bahan kemasan) dengan persentase $(14,958 \%)$, display pada showcase yang terdiri dari variable $\mathrm{X}_{4}$ (display produk) dengan persentase sebesar $(11,413 \%)$ yang mempengaruhi konsumen dalam pembelian daging sapi di Hypermart MATOS.

3. Strategi pemasaran yang dilakukan Hypermart MATOS dari hasil analisis SWOT adalah growth and build yang terdiri dari : 
a. Pengembangan pasar dengan meningkatkan penjualan pada pasar baru yang meningkatkan pasar pada konsumen laki-laki dan anak muda agar senang memasak daging sapi untuk mengisi waktu di hari libur dengan menyebarkan brosur dan demo memasak daging sapi di Hypermart MATOS.

b. Pengembangan produk dengan menawarkan daging sapi atau produk baru yang sejenis untuk meningkatkan penjualan pada pasar yang ada yaitu ibu rumah tangga dengan menetapkan harga yang sesuai karena sebagian besar pasar ibu rumah tangga sensitive terhadap harga.

c. Penetrasi harga dengan meningkatkan penjualan melalui mengefektifkan bauran pemasaran secara agresif pada pelayanan penjual dan promosi di internet dan luar area Hypermart.

\section{Daftar Pustaka}

Adrial. 2010. Potensi sapi Pesisir dan upaya pengembangannya. $\mathrm{J}$. Litbang Peternakan 29, 66-72.

Baiduri, A.A., Sumadi dan Nono, N. 2012. Pendugaan nilai heritabilitas ukuran tubuh pada umur sapih dan umur setahun sapi Bali di Balai Pembibitan Ternak Unggul Sapi Bali, Jembrana, Bali. Buletin Peternakan 36, 1-4.

Becker, A. 1992. Manual of Quantitative Genetics. $4^{\text {ed }}$. Washington State University, Washington.

Hardjosubroto, W. 1994. Aplikasi Pemuliabiakan Ternak di Lapangan. PT Gramedia Widiasarana, Jakarta.

Hartatik, T., Dhany A.M., Tri, S.M.W. dan Endang, B. 2009. Karakteristik dan dan kinerja induk sapi silangan Limousin-Madura dan madura di Kabupaten Sumenep dan Pamekasan. Buletin Peternakan 33, 143-147.

Kaps, M., Posavi, M., Stipic, N. and Mikulic, B. 2000. Genetic evaluation of semen and growth traits of young Simmental bulls in performance test. ACS 65, $15-20$.

Khan, M.A., Khan, M.S. and Waheed, A. $2018 . \quad$ Morphological measurements and their heritability for Sahiwal cattle in Pakistan. The J. Anim. Plant Sci. 28, 1-10.

Maiwashe, A.N., Bradfield, M.J., Theron, H.E. and van Wyk, J.B. 2002. Genetic parameter estimates for body measurements and growth traits in South African Bonsmara cattle. Livest. Prod. Sci. 75, 293300 .

Putra, W.P.B., Sumadi, Tety, H. dan Hendra, S. 2014a. Seleksi awal calon pejantan sapi Aceh berdasarkan berat badan. JSPI 10, 7-12.

Putra, W.P.B., Sumadi, Tety, H. and Hendra, S. 2014b. Analysis of newborn calves measurements for early selection analysis in Aceh bulls at the breeding station. Animal Production 16, 71-77.

Putra, D.E., Sarbaini, Afriani, T., Suahada, H. and Arlina F. 2017. Heritability of growth traits of Simmental cattle in Balai Pembibitan Ternak Unggul Hijauan Pakan Ternak (BPTUHPT) Padang Mengatas, West Sumatera, Indonesia. JPI 19, 170 177.

Rastosari, A., Sumadi dan T. Hartatik. 2016. Ripitabilitas ukuran tubuh 
sapih pada sapi Brahman.

Prosiding Seminar Nasional

Peternakan Berkelanjutan VIII. hal

399- 402, Unpad, Sumedang,

16 November 2016.

Said, S., Putra, W.P.B.,Anwar, S., Agung, P.P. and Aditya, S. 2016. Estimation of most probable producing ability value for calf birth's performance in Sumba Ongole cows. J. Indonesian Trop. Anim. Agric. 41, 53-60.

Said, S., Putra, W.P.B., Anwar, S., Agung, P.P. and Yuhani, H. 2017. Phenotypic, morphometric and characterization and population structure of Pasundan cattle at West Java, Indonesia. Biodiversitas 18, 1638-1645.

Setiadi, B. dan Diwyanto, K. 1997. Karakteristik morfologis sapi Madura. JITV 2, 218- 224.

Tonbesi, T.T., Ngadiono, N. dan Sumadi. 2009. Estimasi potensi dan kinerja sapi Bali di kabupaten Timor Tengah Utara, Propinsi Nusa Tenggara Timur. Buletin Peternakan 33, 30-39.

Utomo, B.N., Noor, R.R., Sumantri, C., Supriatna, I., Gunardi, E.D. dan Tiesnamurti, B. 2012. Keragaman fenotipik kualitatif sapi Kantingan. JITV 17, 1-12.

Warwick, E.J., Astuti, J.W. dan Hardjosubroto, W. 1990. Pemuliaan Ternak. Gadjah Mada University Press, Yogyakarta. 